\title{
ERRATA
}

In the manuscript, "LATE CAMBRIAN CABBAGEHEAD STROMATOLITES FROM SARATOGA SPRINGS, NEW YORK, USA" by Gerald M. Friedman, the following bold line was omitted inbetween pages 43 and 44 of v. 15 , no. 1,2000 .

According to the current flyer of Petrified Sea Gardens (undated, 1998-1999) two new kinds of trilobites were discovered in 1991 (Saratogia calcifera and Dellea landingi) by park volunteers Robert Fick and Ben Tetanus.

\section{ANNUAL INDEX}

SUBJECT INDEX

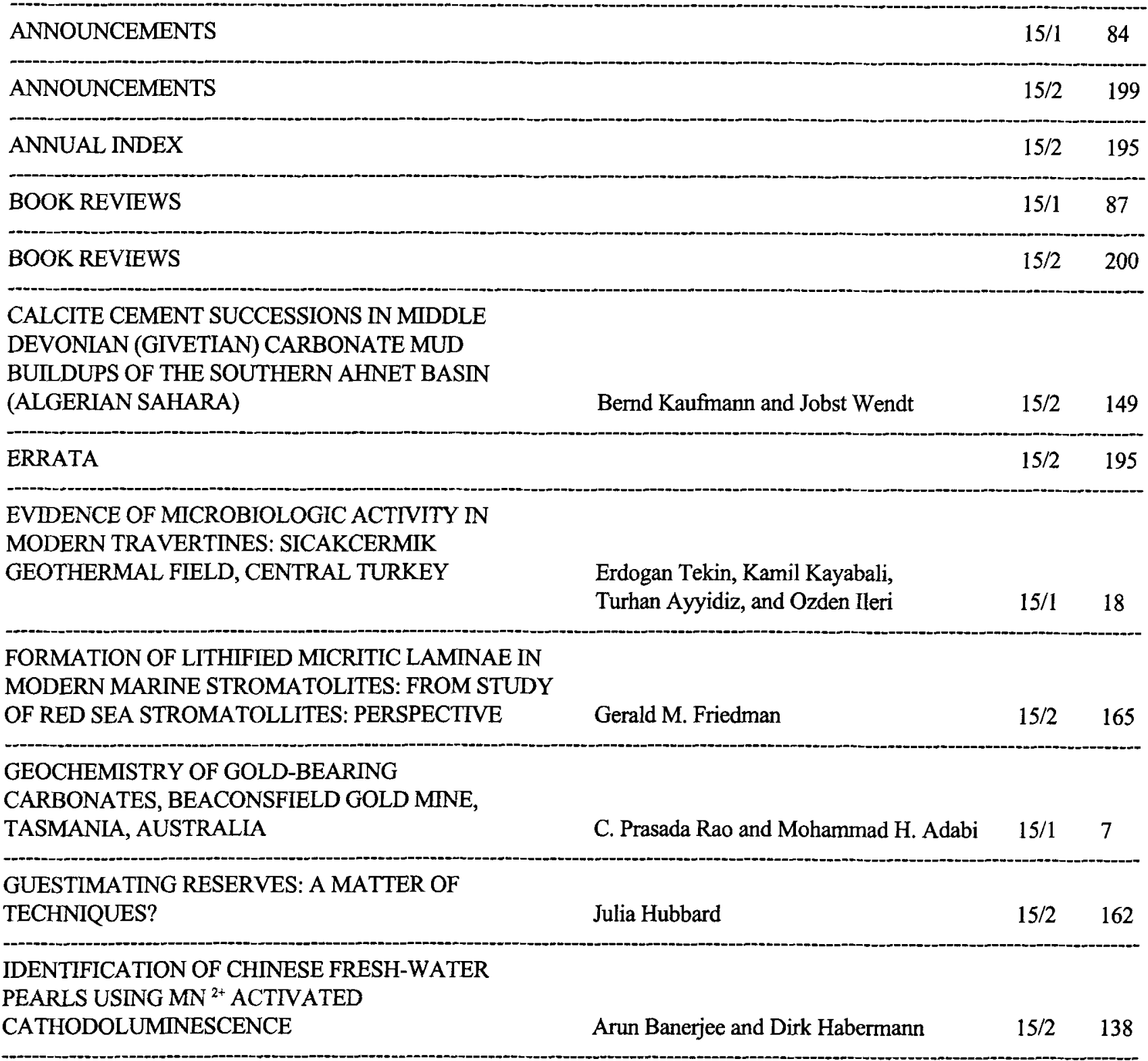

Carbonates and Evaporites, v. 15, no. 2, 2000, p. 195-198. 